\title{
MR. HERMAN WILLEM DAENDELS ALS GOUVERNEUR-GENERAAL TER KUSTE VAN GUINEA
}

\section{I}

DOOR

D. A. HOOGENDIJK hist.dra.

Op 1 December 1813 gaf de divisie-generaal Daendels van het keizerlijke Fransche leger de aan zijn commando toevertrouwde vesting Modlin aan het Russisch-Pruisische leger over. Drie dagen later bood hij schriftelijk den Erfprins van Oranje zijn diensten aan: „Les malheurs de notre patrie reûnissent tous les Hollandais; ils n'ont plus qu'un coeur et un sentiment, celui de voir leur Patrie delivrée du joug des français; de voir Votre Altesse à leur tête comme leur Chef suprême et de voir retourner en Hollande l'Illustre Maison d'Orange Nassau, qui a rendu dans touts les tems des Services les plus signalés à la Patrie" 1). Bij deze ontboezeming liet hij het niet: hij vroeg vergunning in het geallieerde leger dienst te mogen nemen om Nederland te helpen bevrijden en gaf vanuit de verte raad, hoe z.i. een Nederlandsche constitutie naar Engelsch model ingericht en het territoir van de staat uitgebreid moest worden.

Daendels kon naar het Vaderland terugkeeren, maar met gerechtvaardigd wantrouwen bejegende de nieuwe Nederlandsche regeering zijn aanbiedingen en raadgevingen. Hij vond ampel tijd om de verdediging van zijn beleid in Oost-Indië op te stellen en te publiceeren. Achter de schermen ontplooide hij intusschen een groote activiteit, in de stille hoop, in Indië opnieuw een kans te krijgen. Hij ontvouwde voor den Souvereinen Vorst zijn ideeën, hoe de regeering Indië nu moest ontwikkelen, ontwierp daartoe een plan tot een handels-associatie, drong er bij Falck op aan toch den juisten man als Gouverneur-Generaal er heen te sturen (hijzelf wenschte in geen geval in aanmerking te komen!) en bood den tot dit ambt benoemden V. D. Capellen zijn ervaren raad aan 2).

1) Collectie Daendels, No. 139.

2) Collectie Daendels, No. 138-147. 
In Indië bleek echter geen functie voor hem weggelegd. Hij mocht tenslotte het Nederlandsche gezag gaan vertegenwoordigen op de afgelegen, ongezonde en verwaarloosde kust van Guinea. 27 Juli 1815 verscheen het K.B., dat de instructie van den hoofdgebieder Daendels als Gouverneur-Generaal vaststelde 1). Hij kreeg ,,de opper-directie over de Nederlandsche Etablissementen ter kuste van Guinea zoo in het Militaire als in civiele politique en huishoudelijke van wat aard en nature zulks zoude mogen zijn" (Art. 7), ,hij zal als het hoofd der Krijgsmagt zoo te water als te lande het opperkommando hebben" (Art. 9). Ondanks zijn opperbestuur moest hij in zaken van belang de Groote Raad raadplegen, ,welke zal bestaan uit alle de ambtenaren tot den rang van Eerste Resident ingesloten", terwijl hij in de dagelijksche aangelegenheden moest te rade gaan met de hoogste ambtenaren om hem heen, die samen de Kleine Raad vormden (Art. 24). De inlanders moest hij ,,wel en met menschlievendheid" behandelen en hun onderlinge oorlogen zooveel mogelijk voorkomen. Hij moest de verdragen met hen naleven en nieuwe trachten te sluiten (Art. 15, 18, 19, 20). Hij moest een streng toezicht houden op het verbod van slavenhandel (Art. 59). Uitvoerig hield de instructie zich bezig met de economische zijde van Daendels' taak: „Hij zal onverwijld nadat hij zich genoegzaam bekend heeft gemaakt met de ligging der rivieren, de vruchtbaarheid der gronden en de dispositie der inboorlingen om het plan van cultuur bevorderlijk te zijn, daarvan een omstandig verslag aan het Departement van Koophandel en Koloniën doen toekomen" (Art. 55). Hij moest trachten van de inlanders concessies van landerijen te verkrijgen en de inlandsche hoofden aansporen om in plaats van slaven te verkoopen, zich toe te leggen op de teelt van suiker, katoen en dergelijke producten. Hij zeIf en zijn ambtenaren waren vrij om met cultures proeven te nemen (Art. 58, 60, 61). Hij moest evenzoo de handel bevorderen, die niet onderworpen zou zijn aan in- en uitvoerrechten en door ambtenaren en negocianten vrijelijk mocht bedreven worden (Art. 57, 70). Gezien de toestand der Nederlandsche bezittingen was het een indrukwekkend programma. Koning Willem I scheen hem bovendien nog op het hart gedrukt te hebben uiterst zuinig te zijn en de jaarlijksche begrooting niet boven $f 100.000$ te doen uitkomen.

Daendels, die blijkbaar van de Guineesche kust niet op de hoogte was, heeft zich laten voorlichten door een verhandeling van een onbekenden schrijver, gedateerd: Noordwijk, 20 Sept.

1) Collectie Daendels, No. 152. 
1815, een stuk, dat wij nog in zijn papieren aantreffen: ,,Iets over de kust van Guinea, strekkende tot eenige nadere kennis van dat land' 1). Het stuk geeft een zakelijk overzicht van de algemeene gesteldheid ter kuste. Van een eigenlijk Nederlandsch souverein grondgebied was geen sprake, Nederland bezat in 14 etablissementen of forten enkele rechten tegenover de inlanders. Dezen, om het fort wonend, moesten hun handelswaren daar afgeven en den resident in kennis stellen van onderlinge geschillen of oorlog, maar bovenal moesten zij helpen het fort te verdedigen. De Nederlanders van hun kant waren enkel ,,beschermheeren der Inlanders tegen alle hunne vijanden, zonder eenig eigen territoir of eenige schatting of tribût hoegenaamd". Het grootste bezwaar op de kust was echter, dat onze vestigingen niet aaneengesloten lagen, maar onderbroken werden door verschillende Engelsche en Deensche forten.

Het klimaat oordeelde de schrijver niet slechter dan in WestIndië of Java, alleen kon de Europeaan er niet goed tegen. De grond was zeer vruchtbaar, van ,,aartsjeugdelijke vegetatiekracht" en geschikt tot de teelt van allerlei koloniale producten. Daar echter noch de Staat, noch particulieren, noch ambtenaren met succes zich op de exploitatie van plantages konden toeleggen, wegens gebrek aan geld, afzetgebieden en tijd, was de eenige weg, de inlanders tot de teelt van die producten te animeeren en die dan te verhandelen. In dat geval moesten echter rust en orde krachtig gehandhaafd worden en de militaire macht versterkt. De inlanders, hoewel levend in een behoorlijk geordende maatschappij, onderworpen aan onschendbare wetten en gebruiken en geregeerd door landsgrooten (Caboceeërs) of koningen, waren echter slachtoffers van eindelooze onderlinge oorlogen, door de ongelukkige gewoonten van de ,,impia” en het ,„panjaren”. De eerste was het verpanden van personen ter betaling van een schuld, de tweede het opeischen van de persoon van den schuldenaar bij het niet-voldoen van een schuld. Wanneer de schuldenaar nu naar een ander volk vluchtte en dit hem niet uitleverde, dan werden de wegen geblokkeerd, roof aan personen en bezit gepleegd, represailles bleven niet uit en de oorlog ontstond, die akkerbouw om de zeker komende verwoesting zinloos maakte.

Het was dus geen bemoedigend beeld, dat Daendels van blijkbaar deskundige zijde werd geteekend. Bovendien was acht jaren lang het contact met het moederland verbroken geweest en zou hij de eerste zijn, die met eenige anderen het ambtenarencorps kwam

1) Collectie Daendels, No. 180. 
versterken. Een even ongunstige indruk, maar op veel minder zakelijke wijze voorgedragen, krijgen we uit de beschrijving, die De Marrée van de Goudkust gaf 1). Uit zijn beschouwingen is duidelijk, dat het Nederlandsche gezag weinig te beteekenen had en de inlanders de geschenken der blanken aanvaardden, ,,als eene schatting, omdat zij ons in hun land gedogen". (I, bl. 83). De verdediging was totaal vervallen. , Ja, het verval in alles, dat men moet berekenen reeds vóór 25 jaren begonnen te zijn, is zoo groot, dat den moedigsten man de moed ontzinkt, op het denkbeeld van herstel, als hij slechts gevoelen kan wat er ontbreekt". (I, bl. 173).

9 October 1815 vertrok Daendels van de rede van Texel aan boord van Z.M. korvet „Venus”. Enkele ambtenaren vergezelden hem: de contrarolleur A. van Neck, de resident A. van Barneveld, de kolonel der genie Starrenburg. De „Venus” diende niet enkel om hen over te brengen. Zijn ruimen bevatten een lading goederen, die het huis van commercie H. W. Daendels en Co. ter verkoop op de Goudkust ingekocht had. De beide laatstgenoemde ambtenaren en de gezagvoerder behoorden o.a. tot de aandeelhouders, maar Daendels had bijna het geheele kapitaal ( $f 71.000$ van $f$ 101.000) gefourneerd en trad dan ook als hoofdadministrateur op. Het doel der firma was handel te drijven tusschen Guinea en Nederland en zoo een begin te maken met het stimuleeren van dit handelsverkeer. Behalve de „Venus" vertrok voor hun rekening in October 1815 ook de brik „Aurora” en onderweg te Sierra Leone kochten de geassocieerden nog een Portugeesche brik èn tabak, om ter kuste te verkoopen 2).

De reis naar Guinea verliep zonder bijzondere voorvallen. Het Journaal 3), dat Daendels begonnen was bij te houden, laat duidelijk merken, dat de schrijver de kolonisatie-methoden van Engelschen, Spanjaarden en Portugeezen, waarmee hij onderweg kennis maakte, scherp heeft opgenomen om er zijn voordeel mee te doen. Een curieus incident was nog, dat Van Barneveld te Sierra Leone half in het water een steen ontdekte met het opschrift:

1) J. A. de Marrée: ,,Reizen op en beschrijving van de Goudkust van Guinea", 2 dln. 1817. De Marrée was oud-fiscaal en keerde na de komst van Daendels naar Nederland terug. Hij schreef zijn werk om het Nederlandsche publiek, met het oog op Daendels' ondernemingen, beter met de kust bekend te maken.

2) Een copie van de factuur der lading van de ,Venus" en ,Aurora” berust in de Collectie Daendels, No. 155.

3) Collectie Daendels, No. 148: ,Journaal van alle handelingen en voorvallende zaken..."1815-1818; 6 deelen. 


\section{A. Ruiter. J. C. Meppel. \\ Vice Admiralen van Hollant \\ en Westfrieslant. \\ $\mathrm{A}^{\circ} .1664$.}

20 Januari 1816 liet de „Venus” voor Axim het anker vallen. De Commandant-generaal De Veer verwelkomde daar zijn opvolger en Daendels kon direct beginnen met de eerste artikelen van zijn instructie uit te voeren, n.l. alle forten en staatseigendommen te inventariseeren en daarvan binnen 8 dagen een rapport voor het Departement op te stellen. De oorlogstoestand, waarin de negervolken zich bevonden, dwong hem echter dit werk aan enkele commissarissen over te laten, o.a. aan De Marrée, die daardoor in zijn werk nog een up-to-date beschrijving der forten kon geven. Als symptoom van het nieuwe régime, dat hij nu vertegenwoordigde, deelde Daendels na enkele dagen oranje-kokardes uit ter vervanging van de zwarte, ,het teeken van den staat, sedert onheugchelijke tijden en zonder alteratie gedragen geworden" 1).

Een ingewikkelde moeilijkheid moesten het oude en nieuwe bestuur eerst gezamenlijk oplossen, voordat Daendels het gezag kon overnemen. De Veer had hem n.l. moeten mededeelen, dat er een groote achterstand was in de uitbetaling van soldij, salarissen en toelagen. Zoo hadden b.v. in het hoofdfort Elmina de landsslaven in 4 jaar en de militairen in 17 maanden geen uitkeering gehad. Zij hadden als betaling voor de ,kantjesvrouwen"', bij wie de eersten in de kost waren, kostgeldbriefjes gekregen, die in vertrouwen op het Nederlandsche Gouvernement hun waarde behouden hadden, maar nu dan ook onverwijld ingewisseld moesten worden, wilde het panjaren zich niet ongewenscht uitbreiden en het Nederlandsche gezag schade lijden. Na opstelling van een rapport en lange deliberaties daarover besloot de Groote Raad de gages der militairen en landsslaven geheel en aan de landsgrooten de helft der achterstallige kostgelden over 1815 uit te betalen, alles in natura, d.w.z. in Portugeesche tabak, jenever en panegoederen (katoentjes).

Niets belette Daendels nu het bestuur over te nemen, wat 11 Maart 1816 binnen het hoofdfort ceremonieel plaats vond. 14 dagen later scheepte De Veer zich in naar Nederland.

Daendels was naar de Goudkust gekomen met een duidelijke opdracht: de Nederlandsche vestiging zoo spoedig mogelijk rendabel te maken. Dat was niet in een handomdraaien gedaan. Al-

1) Journaal I, 26 Januari 1816. 
lereerst was het noodig, dat de Gouverneur zich een oordeel kon vormen over het binnenland en de rivieren, daar tot nu toe alleen de kust bekend was. Dan kon hij ook de mate van vruchtbaarheid en de geschiktheid tot cultures van de bodem beoordeelen. Toekomstige plantages moesten echter over een behoorlijke verbinding met de kust beschikken en daartoe was de aanleg van wegen noodzakelijk. Wilden de planters echter van die wegen een veilig gebruik maken, dan moest er in het binnenland rust en orde heerschen en een einde komen aan de voortdurende oorlog. Met deze voorbereidende taak begon Daendels op staande voet en de eerste maanden van zijn ambtsperiode zijn er geheel mee gevuld.

Ter Goudkust hadden de Europeesche vestigingen te maken met twee groote negervolken, die in gedurige onderlinge strijd gewikkeld waren: de Assantijnen en de Fantijnen. De eersten bewoonden het binnenland en waren, om de kust te bereiken, gedwongen steeds het gebied van hun nabuurvolken te passeeren, voor deze een unieke gelegenheid tot panjaren en palabbers (geschillen). Het Assantijnsche rijk was een behoorlijk georganiseerde monarchie, waarin geen palabbers voorkwamen. Coemasie was de hoofdplaats met naar schatting ongeveer 60.000 bewoners. Bij de komst van Daendels bevond zich juist de oorlog tusschen Assantijnen en Fantijnen, sedert 1806 aan de gang, in het eindstadium. De koning, ,,Saai", der Assantijnen stond voor het Engelsche fort Cabo Cors, waarbinnen zich vele Fantijnen en ook drie rebellen bevonden, waarom eigenlijk de strijd ontstaan was. De Engelsche Gouverneur had zijn eischen afgeslagen en er waren onderhandelingen geopend. Nu hadden de negers van Elmina, bondgenooten der Assantijnen, Fantijnen, die vandaar naar Cabo Cors gevlucht waren, mishandeld en Daendels vreesde, dat na de vrede de Fantijnen niet zouden nalaten die daad te wreken. Om dit te voorkomen zond hij een boodschapper naar den Assantijnschen generaal met het verzoek, in de komende vrede ook het negerkrom (dorp) van Elmina te begrijpen. De Assantijn nam deze voorslag goed op en dit leidde er toe, dat de Engelsche Gouverneur White Daendels uitnoodigde bij de onderhandelingen vertegenwoordigd te zijn. Zoo begaf zich op Daendels' last de contrarolleur van Neck naar Cabo Cors, die bij zijn terugkeer de bijlegging van het geschil en de uitlevering der drie rebellen kon rapporteeren.

In het begin van April 1816 arriveerde te Elmina een deputatie van den Saai om diens vriendschappelijke gevoelens tegenover Daendels te uiten. Deze zag het groote nut in van een goede verstandhouding met dit machtige negervolk en stelde daarom zijn 
Engelschen collega voor een blanken afgezant naar den Saai te sturen om de pas gesloten vrede te bevestigen en de blokkade der wegen op te heffen. Het gevaar van een opnieuw uitbreken van de strijd was n.l. niet denkbeeldig: de koning, door zijn strijdlustige generaals opzettelijk misleid, geloofde, dat er zich in het Engelsche krom te Groot-Commany nog steeds rebellen ophielden en zoo bleef een Assantijns leger in de buurt vertoeven om bij de eerste gelegenheid de aanval te wagen. Er moest Daendels alles

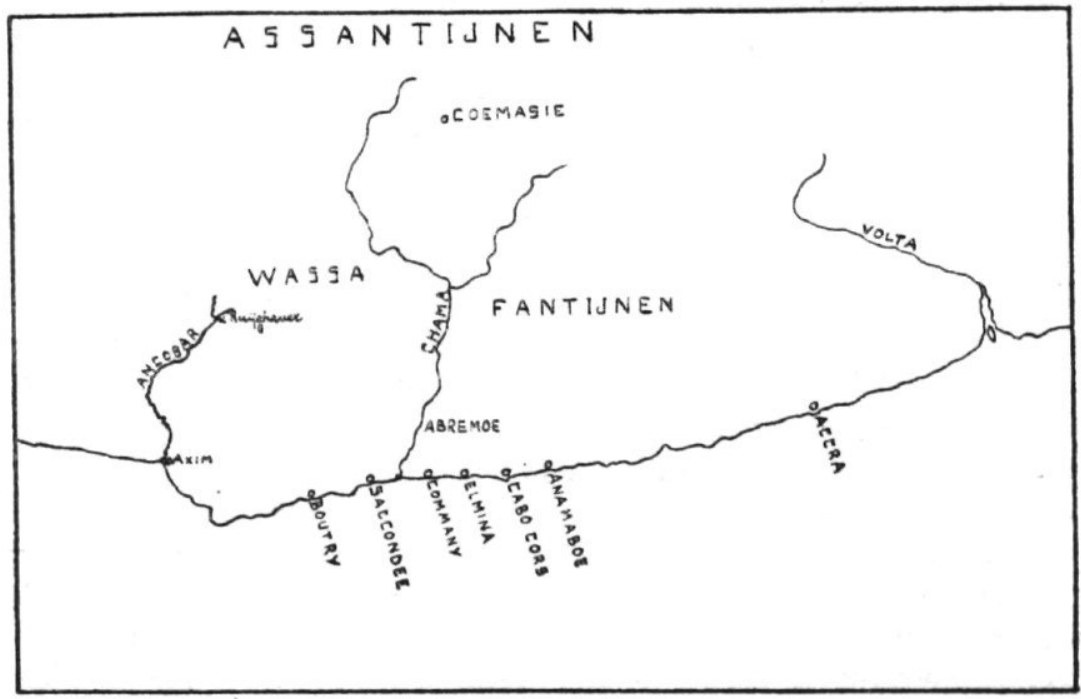

aan gelegen zijn om, met het oog op zijn kolonisatie-plannen, de rust te handhaven en op de Assantijnen een zekere invloed te krijgen.

De eerste assistent W. Huydecoper, een mulat, zou de missie op zich nemen. Hij kreeg een gedetailleerde instructie mee, want Daendels koesterde - terecht - van zijn capaciteiten niet te hooge verwachtingen. Huydecoper moest den koning aanmanen in de bovenlanden de orde te handhaven, niets tegen Engelsch Commany te ondernemen en aan de uitgebreide plannen van Daendels om zijn rijk in beschaving en handelsexpansie te doen deelen, volle medewerking te verleenen. Daendels stelde voor dit laatste punt op een persoonlijke ontmoeting met den Saai te bespreken.

Huydecoper's brieven, in het Journaal geplaatst, laten ons toe zijn reis per hangmat in alle etappen te volgen. Een bewijs, hoe de oorlog de landbouw onmogelijk maakte, was wel, dat aan de 
grenzen van het Assantijnsche rijk hongersnood heerschte, zoodat Huydecoper in drie dagen bijna niets had gegeten. Ook onderweg bleef Daendels zijn afgezant instructies geven. Deze had van de vele geschenken bericht, die hij ontving; mocht de koning die soms voor Daendels meegeven, dan moest Huydecoper om paarden en koeien vragen, die in de kuststreek niet voorkwamen.

Huydecoper's komst bewerkte inderdaad, dat de Assantijnsche generaal Appia bevel kreeg om Groot-Commany niet aan te vallen, maar de daar aanwezige rebellen op te eischen. Onmiddellijk ging Daendels' antwoord terug: er waren geen rebellen, de Saai werd door zijn generaals bedrogen. Daendels' positie was niet te benijden: hij had nog steeds de Assantijnsche deputatie te gast, die allerlei z.g. Fantijnen in het krom van Elmina panjaarde en de Assantijnsche generaals, die met de dorpsgrooten van Elmina onder één hoedje speelden, plunderden de negerdorpen op het Nederlandsche territoir volkomen uit. Elke brief bevatte dan ook het verzoek: Laat de koning die troepen terug trekken! Zoo groot was Daendels' machteloosheid, dat hij niet eens op kon treden tegen Assantijnen, die vanuit zijn eigen forten Engelsche negers voor de kust van hun koren beroofden.

Van een ontmoeting tusschen den koning en Daendels kon niets komen: de eerste durfde zijn land om de onzekere toestanden niet te verlaten. Hij liet nu Daendels vragen, of deze zijn invloed wilde gebruiken om den vorst van Wassa, een aan hem onderhoorige negerstam, te dwingen zijn verontschuldigingen aan te bieden, daar hij in de oorlog partij had gekozen voor de Fantijnen. Daendels trok daarom in persoon naar Groot-Commany, maar slaagde niet. Beter liep het af met onderhandelingen, die beide partijen in het fort van Elmina begonnen. In September kwam een overeenkomst tot stand, die ten overstaan van Daendels bezworen werd: Wassa werd Assantijns vazal en betaalde tribuut; beide volken zouden over en weer de kooplui en hun goederen niet panjaren, weggeloopen slaven teruggeven en moordenaars uitleveren.

Dit verdrag was voor Daendels een stap in de goede richting. Wassa was geen gemakkelijke stam en een overeenkomst zou de rust en handel zeer ten goede komen. Nog een tweede succes kon hij in zijn inboorlingen-politiek boeken. De goede relaties met den Assantijnschen koning hadden de negerhoofden van Elmina voorzichtiger gemaakt en zij waren nu bereid met den Gouverneur een contract te sluiten, een z.g. pen, waarbij hun koning de eed van trouw aflegde en van alle relaties met den vrijburger Jan Nieser, 
hun opperhoofd en voortdurenden tegenstander van Daendels, ontslagen werd, voorzoover zij met deze pen in strijd waren. Voor Daendels was wel van de grootste beteekenis, dat de gezamenlijke ,vaandrigs" der negerkwartieren voortaan de palabbers zouden onderzoeken en, indien moeilijk te beslissen, voor den Gouverneur-Generaal brengen. De koning en zijn grooten zouden ook alle kwesties, die op panjaren konden uitloopen, onderzoeken (15 October 1816). Zoo waren weer elementen van onrust, in de onmiddellijke omgeving van het hoofdfort, weggenomen. Hoe belangrijk de rust onder de negers was, bleek al veertien dagen later, toen de Groote Raad kon vaststellen, dat de weg, die naar Groot-Commany werd aangelegd, al met wagens te berijden was, dank zij de medewerking der bevolking.

Op het eind van het jaar 1816 kon Daendels dan ook in zijn rapport aan het Departement 1) met voldoening constateeren, dat de betrekkingen met de Assantijnen gunstig waren en hij er in geslaagd was, hun koning van een aanval op Wassa terug te houden.

Intusschen had Daendels in drie maanden geen bericht van Huydecoper gehad. Deze man was door den Saai zeer vriendelijk ontvangen, kreeg allerhand geschenken, in 't bijzonder goud, werd vaak als raadsman gebruikt en begon zich in dit negermilieu zoo thuis te voelen, dat hij zijn plichten als ambtenaar en gezant ernstig verwaarloosde. Toen hij eenmaal tot dit besef gekomen was, durfde hij niet meer terug te komen of Daendels zelfs maar te schrijven, uit angst voor reprimandes. Had de Gouverneur hem al niet eens geschreven: ,,Gij weet het tegenwoordig Gouvernement badineert niet en wil dat deszelfs orders die de orders van onzen koning zijn punctueel worden uitgevoerd en dat geene veranderingen of verkeerde explicatiën aan dezelve worden gegeven" 2). Zijn angst verleidde hem tot een onbeschaamde brief, die Daendels niet eens in het Journaal wilde overnemen, maar de voorspraak van den Saai deed den Gouverneur beloven Huydecoper in genade aan te nemen, mits hij van nu af aan (Februari 1817) zijn instructies stipt opvolgde.

1) „, Over den Staat van onze relatien met het Engelsch Gouvernement ter dezer kuste als mede met den Koning van Assantijn, met de Wassasche, Fantijnsche en strandvolkeren"'. Toegevoegd aan Journaal IV en als bijlage voorkomend achter de ,,Geheime memorie aan het Departement van Koophandel en Koloniën over handel en cultures", 1817, Collectie Daendels No. 150.

2) Journaal III, 28 Mei 1816. 
Daendels had een kundigen afgezant wel noodig, want het jaar 1817 bracht nieuwe spanning. De Saai had n.l. de overeenkomst met Wassa, die zijn vertegenwoordiger gesloten had, niet erkend en nu verzocht hij Daendels persoonlijk deze palabber af te maken en bovendien het nog steeds hangende geschil met Engelsch Commany. Hij was over de ,pen" met Elmina zeer te spreken: ,Zijt eens met d'Elminasche want met Uwe onderdanen eens zijnde, word gij ook mijne beste Vriend, want deze menschen zijn alle mijne slaven en onderdanen en als zij $U$ beledigen, laat alles bedaard afmaken en is het al te zwaar, laat mij weten en ik zal het voor U afmaken”. ,Mijn goede vriend, als de Commanysche deze palabber niet met $\mathrm{U}$ afmaken, zal ik de Elminasche bij hun retour volk geven om Commany te gaan vermoorden" 1 ).

Daendels liet den Engelschen Gouverneur direct de eischen van de Assantijnen weten, maar deze grondde zich op het pas gesloten verdrag en weigerde voor Groot-Commany tribuut te betalen, een som, die de doodarme bevolking niet eens kon opbrengen. Zou er weer een oorlog ontbranden en Daendels' werk bedreigen? Hij wierp zijn persoonlijke invloed bij den Saai in de schaal en verzocht hem om zijnentwil Commany te sparen, waaraan de vorst genadiglijk voldeed. Van hun kant stuurden nu de Engelschen ook een deputatie naar Coemasie, die daar Juni 1817 arriveerde. Een vertegenwoordiger van Daendels' handelshuis woonde de ontvangst bij, die niet bijzonder hartelijk was. De koning was boos, dat de Engelschen maar de helft van het door hem geeischte tribuut voor Cabo Cors en Anamaboe meebrachten. De deputatie is er tot October gebleven en bereikte na vele onderhandelingen, dat de palabber over Commany bijgelegd werd en het tribuut naar de zin der Assantijnen geregeld.

(Slot volgt).

1) Journaal V, 5 Januari 1817. 